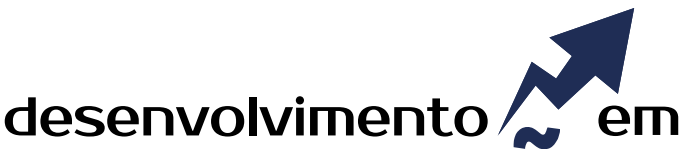 QUESTÂOO
}

\section{Turismo e Sustentabilidade Inter-Relações Entre Práticas Sustentáveis e Experiências Turísticas Memoráveis}

\author{
http://dx.doi.org/10.21527/2237-6453.2019.48.266-281
}

Recebido em: $26 / 8 / 2018$

Aceito em: 19/3/2019

\section{Lúcia Rejane da Rosa Gama Madruga ${ }^{1}$, Valéria Garlet ${ }^{2}$, Camila Pascotini Grellmann ${ }^{3}$}

\begin{abstract}
RESUMO
O turismo potencializa a interação humana e a integração política, cultural e econômica, o que o torna importante para o desenvolvimento das sociedades e a promoção da sustentabilidade. Este trabalho teve como objetivo principal analisar a possível relação entre experiências turísticas memoráveis e práticas sustentáveis. Por meio de uma pesquisa quantitativa (método survey), questionários foram aplicados com 421 turistas, sendo possível identificar suas práticas sustentáveis e percepções sobre experiência turística memorável. A relação entre experiência turística memorável e práticas sustentáveis foi analisada por meio do coeficiente de correlação de Pearson, o qual identificou a correlação significativa entre quase todos os construtos. Observou-se, apenas, que não houve correlação significativa entre as práticas sustentáveis e a renovação. Das dimensões da experiência turística memorável, o conhecimento foi o que apresentou maior associação com as práticas sustentáveis. Constatou-se que quanto maior for a experiência turística memorável, mais tende a ocorrer práticas sustentáveis e vice-versa. Pode-se aí concluir que, a partir do momento em que uma empresa facilita experiências turísticas memoráveis, baseadas nos princípios da sustentabilidade, o turista poderá retornar a sua realidade com novos aprendizados, os quais poderão gerar mudanças de atitudes e contribuir para um mundo melhor. Espera-se, assim, que os resultados apresentados sirvam de contribuição não somente para o âmbito acadêmico, mas também aos gestores de organizações turísticas.
\end{abstract}

Palavras-chave: Práticas sustentáveis. Turismo. Experiências turísticas memoráveis.

TOURISM AND SUSTAINABILITY:

INTER-RELATIONS BETWEEN SUSTAINABLE PRACTICES AND MEMORABLE TOURISM EXPERIENCES

\begin{abstract}
Tourism enhances human interaction and political, cultural and economic integration, making it important for the development of societies and the promotion of sustainability. This work had as main objective to analyze the possible relation between memorable tourist experiences and sustainable practices. Through a quantitative research (survey method), questionnaires were applied with 421 tourists, being possible to identify their sustainable practices and perceptions about a memorable tourist experience. The relationship between memorable tourism experience and sustainable practices was analyzed using the Pearson correlation coefficient, which identified a significant correlation between almost all constructs. There was only no significant correlation between sustainable practices and renewal. From the dimensions of the memorable tourist experience, knowledge was the one that presented the greatest association with sustainable practices. It has been found that the greater the memorable tourist experience, the more sustainable practices are likely to occur and vice versa. It can be concluded that, once a company facilitates memorable tourist experiences, based on the principles of sustainability, tourists can return to their reality with new learning, which can generate changes of attitudes and contribute to a better world. It is hoped, therefore, that the results presented will contribute not only to the academic field, but also to the managers of tourist organizations.
\end{abstract}

Keywords: Sustainable practices. Tourism. Memorable tourist experiences.

\footnotetext{
${ }^{1}$ Doutora em Agronegócios pela Universidade Federal do Rio Grande do Sul (UFRGS). Professora da Universidade Federal de Santa Maria (UFSM). luciagm@ufsm.br

${ }^{2}$ Mestre em Administração pela Universidade Federal de Santa Maria (UFSM). Aluna de Doutorado em Administração pela Universidade Federal de Santa Maria (UFSM). valeriagarlet@yahoo.com.br

${ }^{3}$ Mestre em Administração pela Universidade Federal de Santa Maria (UFSM).camila@eusoufan.com.br
} 
O turismo potencializa a interação humana e a integração política, cultural e econômica, o que o torna importante para o desenvolvimento das sociedades. Sua relação com a sustentabilidade é pertinente e necessária, de modo que a atividade turística venha a ser produtiva economicamente, justa socialmente e correta ambientalmente. Elkington (2001, p. 20) conceitua sustentabilidade como o "princípio de assegurar que nossas ações hoje não limitarão a gama de opções econômicas, sociais e ambientais disponíveis para as gerações futuras". A sustentabilidade turística, assim, pode ser vista como um modo de se fazer turismo satisfazendo as necessidades das pessoas envolvidas, de maneira a não comprometer as futuras gerações de satisfazerem suas próprias necessidades (SWARBROOKE, 2000).

É importante ter consciência de que o crescimento econômico, por meio do turismo, precisa ser viável ao ambiente. Se mal gerida ou consumida, a atividade turística pode causar prejuízos irreversíveis. O consumo sustentável dos serviços turísticos minimiza impactos negativos ambientais e socioculturais e, ao mesmo tempo, promove benefícios econômicos para as comunidades locais e no entorno dos destinos. Para que o consumo sustentável faça parte do cotidiano das pessoas, no entanto, é necessário haver uma transformação social e cultural (JACKSON, 2005) e elaboração de estratégias de intervenção que influenciem os consumidores indiferentes ou pouco sensíveis às questões ambientais, para que eles também passem a agir de maneira a reduzir os impactos negativos de suas ações (RIBEIRO; VEIGA, 2011).

Para Silva e Monticelli (2016, p. 266), práticas sustentáveis "são aquelas que se realizam minimizando ou neutralizando os impactos sociais, culturais e de meio ambiente". Segundo as autoras, as práticas de sustentabilidade são pouco valorizadas pelos viajantes, representando uma oportunidade de formulação de políticas públicas e de iniciativas das organizações que atuam no mercado do turismo para conscientizar a população. Assim, agrega valor ao seu negócio e promove, efetivamente, a sustentabilidade.

A experiência turística é destaque em países como: a Nova Zelândia, que se promove com esportes na natureza e práticas de turismo sustentável; a Espanha e o Caminho de Santiago de Compostela, com uma rota de aproximadamente 800 quilômetros a serem percorridos a pé, de bicicleta ou a cavalo; o Peru e Machu Picchu; a Bolívia e as comunidades no lago Titicaca; o México, que vende uma experiência memorável na península de Yucatán; entre outros.

Este estudo trata-se de uma pesquisa quantitativa baseada no método survey, que teve como objetivo analisar a possível relação entre experiências turísticas memoráveis e práticas sustentáveis. É importante estudar o turismo relacionando-o com a sustentabilidade, posto que, quando o turista sai do seu contexto e passa a viver experiências turísticas (ainda que não memoráveis, como o trabalho propõe), é possível que sejam adquiridos outros hábitos que não incluem práticas sustentáveis. O que se espera, portanto, é que o turismo, por meio das experiências turísticas memoráveis que ele proporciona, esteja alinhado com as práticas sustentáveis. 
O trabalho é importante, pois apresenta tanto a turistas quanto a empresas de turismo uma realidade sobre essa relação turismo-sustentabilidade, que é fundamental, se considerarmos o potencial que o turismo exerce em todos os cantos do mundo e a fundamental necessidade de se pensar e exercer a sustentabilidade sempre, inclusive em momentos de lazer.

Esta pesquisa possui um caráter que integra a área do Turismo e da Administração, e se caracteriza por buscar apresentar contribuições às agências de turismo, organizações em geral, indivíduos, sociedade e meio ambiente. A partir do estudo da relação entre experiência turística memorável e sustentabilidade, tem-se o intuito de mostrar que as práticas sustentáveis dos turistas e das empresas de turismo devem convergir em prol do bem comum do planeta que começa a partir da sustentabilidade.

Desta forma, a lacuna que esta pesquisa busca preencher nos estudos acadêmicos está relacionada justamente ao fato de apresentar as inter-relações entre práticas sustentáveis e experiências turísticas. Quando se trata de estudar a importância do tema sustentabilidade, é fundamental relacioná-la com outros temas que a apresentem como palco ativo, uma vez que ela é intrínseca às áreas sociais, ambientais e econômicas.

\section{FUNDAMENTAÇÃO TEÓRICO-CONCEITUAL}

Em agosto de 2016, o Ministério do Turismo do Brasil lançou o site iniciativassustentaveis.turismo.gov.br, contendo o Mapa da Sustentabilidade, um guia para consultas que promove e incentiva turistas a visitarem destinos que avançam na introdução de boas práticas para a sustentabilidade do turismo. Percebe-se que o turismo, como uma forma positiva de experiência, passou a fazer parte das políticas públicas de algumas regiões brasileiras, mostrando que a temática é interessante e que precisa ser discutida (BRASIL, 2016a).

O Ministério do Turismo (BRASIL, 2016b) parece estar atento à importância da sustentabilidade ambiental, sociocultural, econômica e político-institucional. O governo salienta que, pela compreensão desses quatro princípios, é possível desenvolver ações favoráveis a todos (Quadro 1).

Quadro 1 - Práticas sustentáveis para prestadores de serviços turísticos sugeridas pelo Ministério do Turismo do Brasil com base nos princípios do desenvolvimento sustentável

\begin{tabular}{|c|l|l|}
\hline $\begin{array}{c}\text { Princípios do } \\
\text { desenvolvimento } \\
\text { sustentável }\end{array}$ & \multicolumn{1}{|c|}{ Descrição do princípio } & \multicolumn{1}{|c|}{ Práticas sustentáveis } \\
\hline $\begin{array}{c}\text { Sustentabilidade } \\
\text { Ambiental }\end{array}$ & $\begin{array}{l}\text { Controla os impactos ambientais e a } \\
\text { conservação das áreas naturais e sua } \\
\text { biodiversidade. }\end{array}$ & $\begin{array}{l}\text { Uso racional da água } \\
\text { Eficiência energética } \\
\text { Gestão dos resíduos sólidos } \\
\text { Redução do desperdício }\end{array}$ \\
\hline $\begin{array}{c}\text { Sustentabilidade } \\
\text { Sociocultural }\end{array}$ & $\begin{array}{l}\text { Assegura que o desenvolvimento } \\
\text { preserve a cultura local e os valo- } \\
\text { res morais da população, fortaleça a a } \\
\text { identidade da comunidade e contri- } \\
\text { bua para o seu desenvolvimento. }\end{array}$ & $\begin{array}{l}\text { Respeito à diversidade } \\
\text { Incentivo ao turista a conhecer a cultura } \\
\text { Promoção de eventos culturais com a } \\
\text { participação de artistas locais } \\
\text { Valorização da gastronomia local } \\
\text { Inclusão social } \\
\text { Acessibilidade } \\
\text { Proteção à infância }\end{array}$ \\
\hline
\end{tabular}




\begin{tabular}{|c|c|c|}
\hline $\begin{array}{c}\text { Princípios do } \\
\text { desenvolvimento } \\
\text { sustentável }\end{array}$ & Descrição do princípio & Práticas sustentáveis \\
\hline $\begin{array}{l}\text { Sustentabilidade } \\
\text { Econômica }\end{array}$ & $\begin{array}{l}\text { Estabelece que o desenvolvimento } \\
\text { seja economicamente eficaz, garanta } \\
\text { a equidade na distribuição dos bene- } \\
\text { fícios e gere os recursos de modo que } \\
\text { possam suportar as necessidades das } \\
\text { gerações futuras. }\end{array}$ & $\begin{array}{l}\text { Aquisição de produtos locais } \\
\text { Contratação de mão de obra local } \\
\text { Investimento em programas sociais, cursos } \\
\text { de capacitação e projetos socioculturais }\end{array}$ \\
\hline $\begin{array}{l}\text { Sustentabilidade } \\
\text { Político- } \\
\text { institucional }\end{array}$ & $\begin{array}{l}\text { Assegura a solidez e continuidade } \\
\text { das parcerias e compromissos esta- } \\
\text { belecidos entre os diversos agentes } \\
\text { e agências governamentais dos três } \\
\text { níveis de governo e nas três esferas } \\
\text { de poder, além dos atores situados } \\
\text { no âmbito da sociedade civil. }\end{array}$ & $\begin{array}{l}\text { Participação em entidades representativas } \\
\text { Criação de programas e metas de } \\
\text { sustentabilidade para incentivo aos } \\
\text { colaboradores }\end{array}$ \\
\hline
\end{tabular}

Fonte: Adaptado de BRASIL (2016b).

Segundo Speier (apud CNC, 2014), o turismo apresenta uma abordagem multidimensional e integradora, uma conjugação de elementos para o desenvolvimento sustentável, ligados ao aspecto essencialmente humano.

No Brasil e no mundo percebe-se o esforço em orientar organizações e cidadãos a como pensar e realizar ações sustentáveis. Tanto organizações públicas e privadas, quanto comunidade local e turistas podem, a partir desses princípios, refletir sobre modos de agir mais favoráveis aos aspectos ambiental, social e econômico. Ressalta-se que as práticas de gestão sustentáveis podem ser aplicadas a todas as formas de turismo, em todos os tipos de destinos, bem como o turismo de massa e os diversos segmentos turísticos, de acordo com a Organização Mundial do Turismo - OMT (OMT, 2003).

Mesmo que a atividade turística não seja uma necessidade básica do ser humano, ela pode provocar sensações benéficas a quem a pratica, considerando que "as pessoas precisam vivenciar prazeres particularmente distintos, que envolvam diferentes sentidos, ou que se situem em uma escala diferente daquela com que se deparam em sua vida cotidiana" (URRY, 2001, p. 28).

Quando o turista compra uma viagem, adquire uma experiência que, segundo Swarbrooke e Horner (2002, p. 83), possui algumas fases bem-delineadas: "a fase de antecipação, antes do início da viagem; a fase de consumo, durante a viagem; e a fase da memória, após a viagem". A partir da experiência profissional da pesquisadora, concorda-se com os autores e entende-se que viajar é um processo de expectativa, envolvimento e realização, em que "o caminho percorrido entre a origem e o destino já fazem parte da experiência turística" (VIANNA, 2011, p. 59).

Há muitas oportunidades para o Brasil seguir o caminho do turismo como experiência memorável. Segundo Carvalho (2005), não basta ser o país mais lindo do mundo; é preciso fortalecer o Destino Brasil e toda a cadeia produtiva do turismo. Por isso, cabe também ao meio acadêmico promover reflexões acerca do tema e suas implicações. 
Para facilitar que a experiência se torne memorável (KIM, 2009), as empresas precisam desenvolver ações que incentivem a participação do cliente, além de criar ambientes que apoiem um tema a que suas ações ou seus serviços pertençam. Quando o turista se encontra em um ambiente favorável, imerso em uma atividade, a chance de ele recordar depois é muito maior do que simplesmente estar passivo ao que acontece.

Panosso Netto e Gaeta (2010, p. 26) propõem que "a experiência é essencial para a socialização, o aprendizado, a articulação profissional e a satisfação pessoal", e que a experiência turística tende a marcar positivamente o indivíduo e é um processo intelectual de alargamento do conhecimento.

Kim (2009) apresenta as dimensões da experiência turística memorável: hedonismo (experiência de prazer ao usufruir do turismo), significância (viver uma experiência que tenha significado), novidade (a nova experiência promove sensação de novidade), conhecimento (novas informações, fatos ou experiências que o turista adquire), envolvimento (envolver-se fisicamente com a experiência turística), cultura local (aproveitar as situações típicas do destino turístico escolhido) e renovação (descansar).

\section{MÉTODO}

Essa pesquisa pode ser classificada como descritiva com abordagem quantitativa (GIL, 2008; HAIR et al., 2009), baseada em uma pesquisa bibliográfica e no método survey, este com aplicação de questionários com turistas.

A pesquisa teve como base uma amostragem não probabilística por conveniência (LOPES, 2016). A população foi composta por turistas que consideraram ter vivenciado uma experiência turística memorável. Ao acessar o questionário, o participante era orientado a responder as questões, desde que se incluísse nesse grupo de pessoas.

O convite para participar da pesquisa foi por meio de redes sociais e mensagem eletrônica. Hair et al. (2009) sugerem que o número mínimo de respondentes seja, pelo menos, cinco vezes o número de variáveis a serem analisadas. Sendo assim, o questionário foi composto por 64 variáveis e a amostra constituiu-se em um total de 421 respondentes.

Os dados foram coletados por meio da aplicação de um questionário estruturado conforme o modelo proposto por Aroeira, Dantas e Gosling (2016) e Silva e MonticeIli (2016), incluindo questões baseadas nas concepções sobre turismo sustentável do Ministério do Turismo do Brasil. Assim, foi possível identificar as percepções dos turistas a partir das dimensões subjacentes da experiência turística memorável: hedonismo, envolvimento, novidade, cultura local, conhecimento, renovação e significância (KIM, 2009) e averiguar as práticas sustentáveis dos turistas durante as suas viagens. Para os dados quantitativos, a análise de dados foi realizada por meio da técnica de estatísticas descritivas e cruzamento de variáveis.

Tanto as questões específicas sobre práticas sustentáveis quanto as sobre experiência turística memorável, foram avaliadas por meio da escala Likert de 5 pontos sendo de " 1 = discordo totalmente" a " 5 = concordo totalmente". 
A fim de analisar as inter-relações entre os dois constructos, foi feito o teste de correlação de Pearson. A partir da pesquisa foi possível comparar alguns resultados identificados por Silva e Monticelli (2016) e Aroeira, Dantas e Gosling (2016). Todas as análises estatísticas foram realizadas com o auxílio do Excel e software SPSS - Statistical Package for Social Sciences - e o nível de significância considerado foi de 5\%.

A uniformização dos dados foi utilizada para converter os dados obtidos pelas escalas ordinais para escalas de razão (LOPES, 2016), o que permitiu efetuar as análises e as comparações necessárias dos construtos com o coeficiente padrão de $0 \%$ a $100 \%$. 0 método matemático utilizado considera a soma de todas as respostas captadas pelas variáveis de cada construto com base na Escala Likert de 5 pontos (valores de 1 a 5), conforme Equação (1):

$$
P_{c}=100 *\left(\frac{\sum \text { respostas }- \text { Mínimo }}{\text { Máximo }- \text { Mínimo }}\right)
$$

onde:

c = construto analisado (Práticas Sustentáveis e Experiências Turísticas Memoráveis);

$\sum$ respostas = somatório das respostas de todas as variáveis do construto analisado;

Mínimo = menor soma possível das respostas;

Máximo = maior soma possível das respostas.

Esta pesquisa foi aprovada no Comitê de Ética em Pesquisa da instituição dos pesquisadores. Ela foi esclarecida a todos os indivíduos participantes e a confidencialidade e o sigilo da identidade destes estão garantidos.

\section{RESULTADOS E DISCUSSÃO}

Este capítulo trata da análise e discussão dos resultados com base nos objetivos do trabalho e na fundamentação teórica. Os resultados decorreram da análise de um grupo de turistas com o seguinte perfil (Quadro 2):

Quadro 2-Perfil dos respondentes

\begin{tabular}{|c|c|c|c|}
\hline Característica & Opções & Quantidade & $\%$ \\
\hline \multirow{4}{*}{ Estado onde reside } & Rio Grande do Sul & 358 & 85,04 \\
\hline & São Paulo & 25 & 5,94 \\
\hline & Santa Catarina & 23 & 5,46 \\
\hline & Outros Estados & 15 & 3,56 \\
\hline \multirow{3}{*}{$\begin{array}{l}\text { Frequência com que } \\
\text { viaja }\end{array}$} & $1 x$ ou menos por ano & 177 & 42,04 \\
\hline & $2 x$ por ano & 158 & 37,53 \\
\hline & $3 x$ ou mais por ano & 86 & 20,43 \\
\hline \multirow{6}{*}{ Acompanhamento } & Família & 276 & 65,56 \\
\hline & Cônjuge/namorado(a) & 174 & 41,33 \\
\hline & Amigos & 153 & 36,34 \\
\hline & Sozinho(a) & 51 & 12,11 \\
\hline & Em grupo & 41 & 9,74 \\
\hline & Colegas de trabalho & 22 & 5,23 \\
\hline
\end{tabular}




\begin{tabular}{|c|c|c|c|}
\hline Característica & Opções & Quantidade & $\%$ \\
\hline \multirow{10}{*}{ Faixa etária } & 13 a 18 anos & 21 & 4,99 \\
\hline & 19 a 24 anos & 48 & 11,40 \\
\hline & 25 a 30 anos & 86 & 20,43 \\
\hline & 31 a 36 anos & 68 & 16,15 \\
\hline & 37 a 42 anos & 53 & 12,59 \\
\hline & 43 a 48 anos & 37 & 8,79 \\
\hline & 49 a 54 anos & 41 & 9,74 \\
\hline & 55 a 60 anos & 47 & 11,16 \\
\hline & 61 a 66 anos & 14 & 3,33 \\
\hline & 67 a 72 anos & 6 & 1,43 \\
\hline \multirow{3}{*}{ Gênero } & Feminino & 334 & 79,33 \\
\hline & Masculino & 85 & 20,19 \\
\hline & Transgênero & 2 & 0,48 \\
\hline \multirow{4}{*}{ Estado civil } & Casado(a) & 186 & 44,18 \\
\hline & Solteiro(a) & 204 & 48,46 \\
\hline & Separado(a) & 24 & 5,70 \\
\hline & Viúvo(a) & 7 & 1,66 \\
\hline \multirow{3}{*}{$\begin{array}{c}\text { Grau de escolari- } \\
\text { dade }\end{array}$} & Pós-Graduação & 221 & 52,49 \\
\hline & Ensino Superior Completo & 115 & 27,32 \\
\hline & Ensino Superior Incompleto & 60 & 14,25 \\
\hline \multirow{4}{*}{$\begin{array}{c}\text { Grau de escolari- } \\
\text { dade }\end{array}$} & Ensino Médio Completo & 15 & 3,56 \\
\hline & Ensino Médio Incompleto & 3 & 0,71 \\
\hline & Ensino Fundamental Completo & 4 & 0,95 \\
\hline & Ensino Fundamental Incompleto & 3 & 0,71 \\
\hline \multirow{5}{*}{ Renda mensal } & Até $\mathrm{R} \$ 1.000,00$ & 29 & 6,89 \\
\hline & De $\mathrm{R} \$ 1.001,00$ a $\mathrm{R} \$ 3.000,00$ & 106 & 25,18 \\
\hline & De $\mathrm{R} \$ 3.001,00$ a $\mathrm{R} \$ 5.000,00$ & 95 & 22,57 \\
\hline & De $\mathrm{R} \$ 5.001,00$ a $\mathrm{R} \$ 8.000,00$ & 90 & 21,38 \\
\hline & Acima de $\mathrm{R} \$ 8.000,00$ & 101 & 23,99 \\
\hline
\end{tabular}

Fonte: Dados da pesquisa.

Em razão de as pesquisadoras residirem em Santa Maria (RS), sendo uma delas gestora de uma agência de viagens, e a pesquisa ter sido baseada no envio dos questionários por meio de suas redes sociais, 255 pessoas $(60,57 \%)$ que responderam à pesquisa moram na cidade. No que se refere à frequência com que o turista viaja, percebe-se que $57,96 \%$ dos respondentes viaja duas vezes ou mais por ano.

Quanto ao acompanhamento, os respondentes poderiam selecionar mais de uma opção de com quem costumam viajar. Esses dados mostram que apenas 51 respondentes costumam viajar sozinhos, ou seja, a maior parte viaja com familiares, cônjuges/ namorado(a) e amigos, o que pode ser algo rentável para organizações turísticas, sobretudo para as agências de viagens. 
Para realizar as divisões das faixas etárias foi realizado o cálculo conforme a fórmula de Sturges: $k=1+3,322(\log 10 n)$, onde: $k=$ número de classes $(10)$ e $n=$ total de respondentes (421). A amplitude de cada classe é calculada como $h=$ máx. - mín./k. Neste caso: $72-13 / 10=6$.

No que se refere ao gênero, a pesquisa foi respondida predominantemente por mulheres (334), 85 respondentes são do gênero masculino e somente 2 pessoas consideram-se transgêneras.

No que concerne ao grau de escolaridade, 79,81\% possui Pós-Graduação ou Ensino Superior completo. Assim, considera-se um alto nível de instrução por parte dos respondentes. Indo ao encontro desse resultado, em 2009 o Ministério do Turismo (BRASIL, 2009) realizou uma pesquisa sobre hábitos de consumo do turismo brasileiro e concluiu que, dos 1.479 consumidores que viajaram em 2007 e 2008 no Brasil, 51,3\% possuía ensino superior.

à renda mensal, há um significativo equilíbrio entre as faixas de renda, representando que viajar é possível para as mais diversas classes sociais. Para Speier (apud CNC, 2014), o turismo é capaz de promover a aceleração econômica e o incremento nas áreas social, cultural e ambiental; é uma força para propulsionar a compreensão mútua, a cooperação entre os países e a melhoria da qualidade de vida, sobretudo das camadas carentes.

Com o intuito de verificar a confiabilidade do instrumento de pesquisa, utilizou-se o Alpha de Cronbach (Tabela 1). Os resultados deste índice variam entre 0 e 1, sendo o limite inferior aceitável igual a 0,60. Cabe destacar, entretanto, que quanto mais próximo a 1,00 maior é a consistência interna das variáveis que formam os fatores.

Tabela 1 - Análise de Confiabilidade: coeficiente Alpha de Cronbach

\begin{tabular}{|c|c|}
\hline Construto & alpha de cronbach \\
\hline Práticas sustentáveis & 0,799 \\
\hline Experiência turística memorável (geral) & 0,923 \\
Hedonismo & 0,806 \\
Novidade & 0,834 \\
Cultura local & 0,730 \\
Conhecimento & 0,759 \\
Renovação & 0,809 \\
Significância & 0,703 \\
Envolvimento & 0,810 \\
\hline
\end{tabular}

Fonte: Dados da pesquisa.

Assim, pelos dados de confiabilidade apresentados, pode-se afirmar que os construtos foram suficientemente consistentes.

A partir da padronização dos dados, identificação da média padrão (de 0\% a 100\%) e intensidade do construto (Tabela 2), foi possível desenvolver a relação entre eles por meio da Correlação de Pearson (Tabela 3). 
Tabela 2 - Média padrão e grau de intensidade dos construtos

\begin{tabular}{|c|c|c|}
\hline Construto & Média Padrão \% & Grau \\
\hline Práticas Sustentáveis (PS) & 67,23 & ALTO \\
\hline Experiência Turística Memorável (EM) & 88,14 & ALTO \\
Hedonismo (HED) & 94,64 & ALTO \\
Conhecimento (CON) & 88,70 & ALTO \\
Envolvimento (ENV) & 88,28 & ALTO \\
Novidade (NOV) & 88,27 & ALTO \\
Renovação (REN) & 87,20 & ALTO \\
Cultura Local (CL) & 84,09 & ALTO \\
Significância (SIG) & 83,89 & ALTO \\
\hline
\end{tabular}

Nota: Grau padronizado referente à intensidade média aferida.

Fonte: Dados da pesquisa.

Ao analisar cada construto, verificou-se que todos apresentaram um alto grau de intensidade, o que foi considerado satisfatório ao estudo. Acredita-se, no entanto, que a sustentabilidade pode ser mais bem praticada pelos turistas, pois a média padrão das práticas sustentáveis $(67,23 \%)$ demonstrou-se mais baixa que a média padrão da experiência turística memorável (88,14\%). Swarbrooke (2000) salienta que o turismo sustentável é economicamente viável e busca preservar os recursos dos quais o turismo dependerá no futuro (meio ambiente físico e a constituição social da comunidade local). O autor também ressalta que é preciso concentrar mais atenção às dimensões socioculturais do turismo, em busca da sustentabilidade.

Entre as dimensões da experiência turística memorável, os sentimentos de prazer durante o consumo de produtos turísticos foram os que mais se destacaram. Já a sensação de vivenciar algo de grande valor ou significado teve intensidade alta, porém, entre as dimensões, foi a que menos teve relevância. Corroborando com o presente estudo, a pesquisa de Aroeira, Dantas e Gosling (2016) validou a hipótese de que a experiência turística memorável influencia positivamente o hedonismo (sensação de prazer), porém rejeita a hipótese no caso de a experiência turística memorável influenciar positivamente a significância.

Tabela 3 - Correlação entre os construtos

\begin{tabular}{|c|c|c|c|c|c|c|c|c|c|c|}
\hline \multirow{2}{*}{\multicolumn{2}{|c|}{ HED }} & \multicolumn{9}{|c|}{ SIGNIFICÂNCIA (valor de p) } \\
\hline & & NOV & $\mathrm{CL}$ & CON & REN & SIG & ENV & EM & PS & \\
\hline \multirow{9}{*}{ 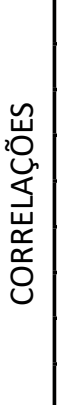 } & HED & 1,0000 & $p=0,00$ & $p=, 000$ & $p=0,00$ & $p=0,00$ & $p=0,00$ & $p=0,00$ & $p=0,00$ & $p=, 000$ \\
\hline & NOV &, 5720 & 1,0000 & $p=, 000$ & $p=0,00$ & $p=0,00$ & $p=0,00$ & $p=0,00$ & $p=0,00$ & $p=, 023$ \\
\hline & $C L$ & ,3232 & ,3486 & 1,0000 & $p=0,00$ & $p=0,00$ & $p=0,00$ & $p=0,00$ & $p=0,00$ & $p=, 000$ \\
\hline & CON & ,4452 & ,4309 &, 5914 & 1,0000 & $p=0,00$ & $p=0,00$ & $p=0,00$ & $p=0,00$ & $p=, 000$ \\
\hline & REN &, 5161 &, 5536 & ,3831 & ,3708 & 1,0000 & $p=0,00$ & $p=0,00$ & $p=0,00$ & $p=, 072$ \\
\hline & SIG & ,4490 & ,6081 & ,4266 &, 4559 &, 6005 & 1,0000 & $p=0,00$ & $p=0,00$ & $p=0,00$ \\
\hline & ENV & ,5098 & ,5297 & ,3166 & ,4482 & ,4648 & ,6077 & 1,0000 & $p=0,00$ & $p=0,00$ \\
\hline & $E M$ & ,7148 & ,7967 & ,6390 & ,6956 & ,7775 & 8124 & ,7404 & 1,0000 & $p=0,00$ \\
\hline & PS & 1726, & 1108, & 2667, & 2866, & 0879, & 2417, & 1991, & 2513, & 1,0000 \\
\hline
\end{tabular}

Nota: Construtos: "HED" - Hedonismo; "NOV" - Novidade; "CL" - Cultura Local; "CON" - Conhecimento; "REN" - Renovação; "SIG" - Significância; “ENV” - Envolvimento; “EM” - Experiência Turística Memorável; “PS” - Práticas Sustentáveis. 
Os testes estatísticos realizados indicaram que, embora distintos entre si, a maioria dos construtos analisados demonstraram-se correlacionados. O padrão de correlação mínimo aceitável neste estudo foi de $p \leq 0,05$ (significância). Pestana e Gageiro (2003) sugerem que as variações do coeficiente de correlação entre 0,01 e 0,39 são classificadas como associações baixas, entre 0,4 e 0,69 são associações moderadas e entre 0,7 e 1 são consideradas altas.

Apenas não houve correlação significativa entre os construtos práticas sustentáveis e renovação. Das dimensões da experiência turística memorável, o conhecimento foi o que apresentou maior associação com as práticas sustentáveis. As experiências provocadas pelas práticas turísticas sustentáveis podem tornar-se um modo de aprendizado e de amadurecimento pessoal e coletivo, uma vez que o conhecimento pode ser promovido por diferentes atores sociais de maneira tanto explícita quanto implícita (CUNHA, 2009).

Apesar de baixa correlação, ainda assim houve significância positiva entre práticas sustentáveis e experiência turística memorável. Isso quer dizer que a tendência é que quanto maior for a experiência turística memorável, mais tende a ocorrer práticas sustentáveis e vice-versa (Figura 1).

Figura 1 - Linha de tendência: Práticas Sustentáveis x Experiências Turísticas Memoráveis

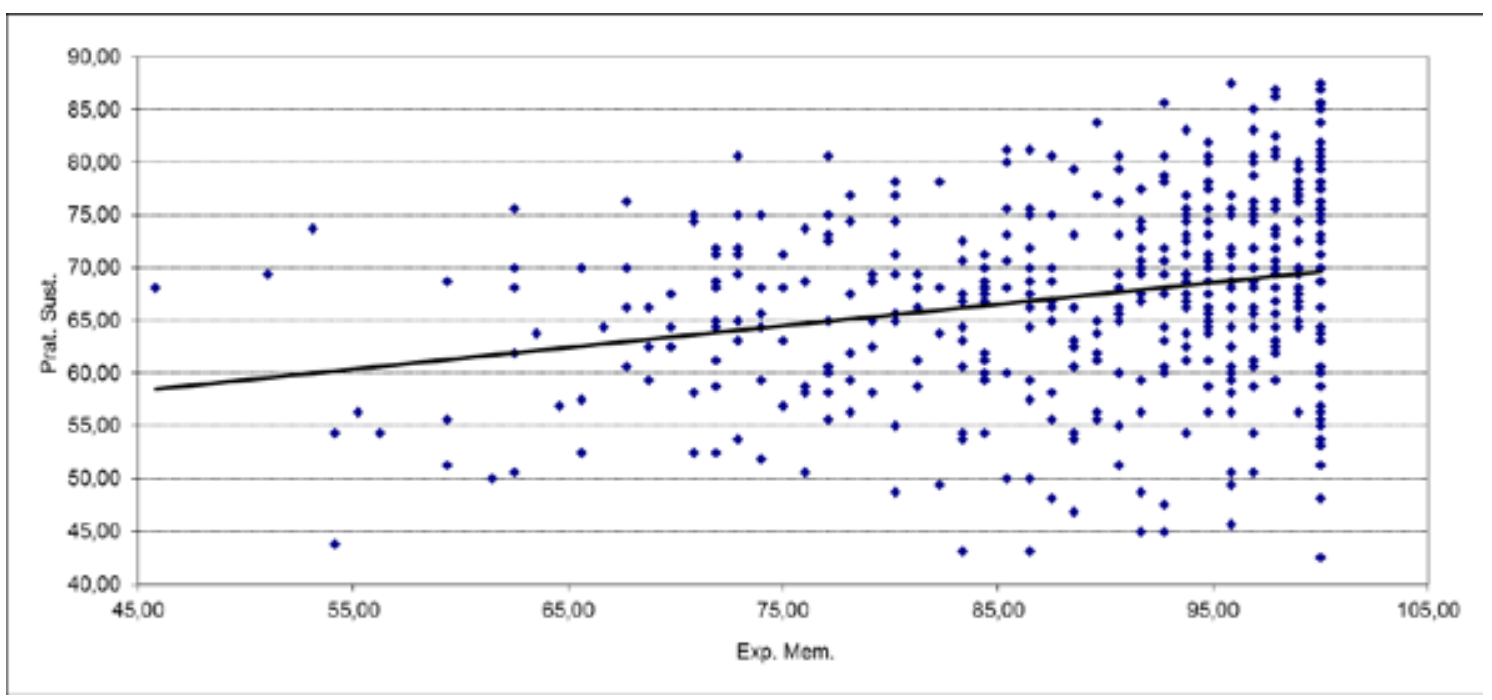

Fonte: Dados da pesquisa.

A seguir é feita a análise de acordo com as características dos participantes.

\section{Análise de Diferenças}

Esta seção apresenta testes buscando verificar diferenças de médias entre os construtos e a característica dos participantes do estudo. A homocedasticidade foi feita pelo teste de Levene e todos os resultados indicaram haver igualdade de variância, situação desejada para os teste-t e Anova (HAIR JR. et al., 2009). A Tabela 4 apresenta a relação dos construtos com o gênero dos participantes. 
Tabela 4 - Análise de médias dos construtos e gênero

\begin{tabular}{c|c|c|c|c}
\hline \multirow{2}{*}{ Construto } & Gênero & Média & Desvio Padrão & \multirow{2}{*}{ p-valor } \\
\hline \multirow{2}{*}{ PS } & Feminino & 3,6339 & 0,67717 & \multirow{2}{*}{0,992} \\
\cline { 2 - 4 } & Masculino & 3,6356 & 0,65690 & \\
\hline \multirow{2}{*}{ EM } & Feminino & 4,2944 & 0,42240 & \multirow{2}{*}{0,218} \\
\cline { 2 - 4 } & Masculino & 4,4694 & 0,51985 & \\
\hline
\end{tabular}

Fonte: Dados da pesquisa.

Os resultados mostraram que não houve diferença significativa das médias das respostas para a experiência turística memorável e para práticas sustentáveis entre homens e mulheres. Quando categorizados pelo estado civil, não houve diferença significativa das médias das respostas para práticas sustentáveis (Tabela 5).

Tabela 5 - Análise de médias dos construtos e estado civil

\begin{tabular}{l|c|c|c|c}
\hline Construto & Estado Civil & Média & Desvio Padrão & p-valor \\
\hline \multirow{4}{*}{ PS } & Casado(a) & 3,6642 & 0,67621 & \multirow{3}{*}{0,335} \\
\cline { 2 - 4 } & Solteiro(a) & 3,5831 & 0,67762 & \\
\cline { 2 - 4 } & Separado(a) & 3,7753 & 0,66411 & \multirow{3}{*}{$0,017^{*}$} \\
\cline { 2 - 4 } & Viúvo(a) & 3,8686 & 0,78779 & \\
\hline \multirow{4}{*}{ EM } & Casado(a) & 4,5271 & 0,20632 & \\
\cline { 2 - 4 } & Solteiro(a) & 4,5352 & 0,19205 & \\
\cline { 2 - 4 } & Separado(a) & 4,4827 & 0,24821 & \\
\cline { 2 - 4 } & Viúvo(a) & 4,3513 & 0,23057 & \\
\cline { 2 - 4 } & & \multicolumn{2}{c}{} & \\
\end{tabular}

Nota: *A diferença média é significativa no nível 0,05.

Fonte: Dados da pesquisa.

Já para a experiência turística memorável houve diferença significativa entre os estados civis e, por isso, foi realizado o teste de Tukey (Tabela 6).

Tabela 6 - Teste de Tukey: comparações múltiplas para estado civil

\begin{tabular}{ccc}
\hline E. Civil & E. Civil & p-valor \\
\hline Casado(a) & Solteiro(a) & 0,999 \\
& Separado(a) & 0,897 \\
& Viúvo(a) & $0,034^{*}$ \\
\hline Solteiro(a) & Separado(a) & 0,842 \\
& Viúvo(a) & $0,024^{*}$ \\
\hline Separado(a) & Viúvo(a) & 0,173 \\
\hline
\end{tabular}

Nota: *A diferença média é significativa no nível 0,05.

Fonte: Dados da pesquisa.

Assim, existe diferença significativa entre as médias das respostas para experiência turística memorável entre os estados civis casado e viúvo; solteiro e viúvo. Ao usar as médias como parâmetro de comparação, percebe-se que os casados e solteiros tendem a ter uma experiência mais memorável que os viúvos. Isso pode ser pelo fato de essas pessoas não se sentirem tão entusiasmadas em viajar, uma vez que perderam o 
seu cônjuge. Independente do estado civil, e inclusive para melhorar situações de relacionamentos (ou a falta deles), o que pode interessar bastante em uma viagem turística é o objetivo que "consiste em descobrir a si mesmo, assumir sua história pessoal e, ainda, escolher os caminhos que restam para completar a sua existência" (PANOSSO NETTO; GAETA, 2010, p. 37).

Para facilitar a análise, os graus de escolaridade foram agrupados em Ensino Fundamental incompleto até Superior incompleto e Ensino Superior completo e Pós-Graduação (Tabela 7).

Tabela 7 - Análise de médias dos construtos e escolaridade

\begin{tabular}{|c|c|c|c|c|}
\hline Construto & Escolaridade & Média & Desvio Padrão & p-valor \\
\hline \multirow{2}{*}{ PS } & $\begin{array}{l}\text { Ensino Fundamental incompleto até } \\
\text { Superior incompleto }\end{array}$ & 3,5797 & 0,66869 & \multirow{2}{*}{0,662} \\
\hline & $\begin{array}{l}\text { Ensino Superior completo e Pós-Gra- } \\
\text { duação }\end{array}$ & 3,6492 & 0,67500 & \\
\hline \multirow{2}{*}{ EM } & $\begin{array}{l}\text { Ensino Fundamental incompleto até } \\
\text { Superior incompleto }\end{array}$ & 4,5980 & 0,18023 & \multirow{2}{*}{0,106} \\
\hline & $\begin{array}{l}\text { Ensino Superior completo e Pós-Gra- } \\
\text { duação }\end{array}$ & 4,5072 & 0,20110 & \\
\hline
\end{tabular}

Fonte: Dados da pesquisa.

Para a categoria escolaridade não houve diferença significativa das médias das respostas para as práticas sustentáveis e experiência turística memorável.

Os agrupamentos das faixas etárias também se fizeram necessários a fim de otimizar a análise. Conforme o Estatuto da Criança e do Adolescente (BRASIL, 1990) e o Estatuto do Idoso (BRASIL, 2003), é considerado "jovem" o indivíduo com idade até 17 anos, "adulto" entre 18 e 59 anos e "idoso" a partir de 60 anos. A análise das médias dos construtos com a faixa etária é apresentada na Tabela 8.

Tabela 8 - Análise de médias dos construtos e faixa etária

\begin{tabular}{l|c|c|c|c}
\hline Construto & Faixa Etária & Média & Desvio Padrão & p-valor \\
\hline \multirow{3}{*}{ PS } & Jovem & 3,3569 & 0,67026 & \multirow{3}{*}{$0,005^{*}$} \\
\cline { 2 - 4 } & Adulto & 3,6278 & 0,67645 & \\
\cline { 2 - 4 } & Idoso & 3,8922 & 0,69373 & \\
\hline \multirow{3}{*}{ EM } & Jovem & 4,5417 & 0,22292 & \multirow{3}{*}{$0,010^{*}$} \\
\cline { 2 - 4 } & Adulto & 4,5358 & 0,19300 & \\
\cline { 2 - 4 } & Idoso & 4,3600 & 0,26402 & \\
\hline
\end{tabular}

Nota: *A diferença média é significativa no nível 0,05.

Fonte: Dados da pesquisa.

Tanto para práticas sustentáveis quanto para experiência turística memorável, houve diferença significativa das médias das respostas com relação à faixa etária. Os testes de Tukey (Tabela 9 e Tabela 10) mostram quem diferiu de quem entre os grupos. 
Tabela 9 - Teste de Tukey: comparações múltiplas para faixa etária (PS)

\begin{tabular}{|c|c|c|}
\hline F. Etária & F. Etária & p-valor \\
\hline \multirow{2}{*}{ Jovem } & Adulto & 0,214 \\
\cline { 2 - 3 } & Idoso & $0,003^{*}$ \\
\hline Adulto & Idoso & 0,230 \\
\hline
\end{tabular}

Nota: *A diferença média é significativa no nível 0,05.

Fonte: Dados da pesquisa.

Entre jovem e idoso houve diferença significativa das médias das respostas para as práticas sustentáveis. As pessoas com idade acima de 60 anos parecem realizar mais práticas sustentáveis que os jovens de até 17 anos.

Tabela 10 - Teste de Tukey: comparações múltiplas para faixa etária (EM)

\begin{tabular}{|c|c|c|}
\hline F. Etária & F. Etária & p-valor \\
\hline \multirow{2}{*}{ Jovem } & Adulto & 0,996 \\
\cline { 2 - 3 } & Idoso & $0,020^{*}$ \\
\hline Adulto & Idoso & $0,026^{*}$ \\
\hline
\end{tabular}

Nota: *A diferença média é significativa no nível 0,05.

Fonte: Dados da pesquisa.

A diferença foi significativa se se comparar a experiência turística memorável dos participantes jovens com idosos e adultos com idosos. Apesar de existir uma intensidade alta para todas as faixas etárias, pela análise de médias percebe-se que a experiência turística tende a ser mais memorável para pessoas de até 60 anos de idade.

A categoria renda mensal também foi relacionada aos construtos, conforme Tabela 11 .

Tabela 11 - Análise de médias dos construtos e renda mensal

\begin{tabular}{|c|c|c|c|c|}
\hline Construto & Renda Mensal & Média & Desvio Padrão & p-valor \\
\hline \multirow{5}{*}{ PS } & Até $\mathrm{R} \$ 1.000,00$ & 3,5486 & 0,70069 & \multirow{5}{*}{0,838} \\
\hline & De $R \$ 1.001,00$ a $R \$ 3.000,00$ & 3,5942 & 0,70565 & \\
\hline & De $\mathrm{R} \$ 3.001,00$ a $\mathrm{R} \$ 5.000,00$ & 3,6175 & 0,68412 & \\
\hline & De $R \$ 5.001,00$ a $R \$ 8.000,00$ & 3,6931 & 0,63202 & \\
\hline & Acima de $\mathrm{R} \$ \mathbf{8 . 0 0 0 , 0 0}$ & 3,6656 & 0,67563 & \\
\hline \multirow{5}{*}{ EM } & Até $\mathrm{R} \$ 1.000,00$ & 4,5245 & 0,23913 & \multirow{5}{*}{0,600} \\
\hline & De $R \$ 1.001,00$ a $R \$ 3.000,00$ & 4,5024 & 0,21586 & \\
\hline & De $R \$ 3.001,00$ a $R \$ 5.000,00$ & 4,4816 & 0,19962 & \\
\hline & De $R \$ 5.001,00$ a $R \$ 8.000,00$ & 4,5635 & 0,18900 & \\
\hline & Acima de $R \$ 8.000,00$ & 4,5577 & 0,18768 & \\
\hline
\end{tabular}

Fonte: Dados da pesquisa.

Os resultados identificaram que não houve diferença significativa das médias das respostas para a experiência memorável e práticas sustentáveis quando categorizados pela renda mensal. 


\section{CONSIDERAÇÕES FINAIS}

O caráter interdisciplinar do estudo buscou a integração do Turismo e da Administração com o objetivo de trazer contribuições às organizações, aos indivíduos e ao meio ambiente. A partir do momento em que são aprofundados os estudos relacionados à experiência turística e sustentabilidade, espera-se que as práticas dos indivíduos e das empresas turísticas, sobretudo agências de viagens e hotéis, possam repercutir de maneira favorável visando o bem comum da sociedade.

Este trabalho teve como objetivo principal analisar a possível relação entre experiências turísticas memoráveis e práticas sustentáveis. Por meio da aplicação de questionários foi possível identificar práticas sustentáveis de 421 turistas e suas percepções sobre experiência turística memorável. No que se refere ao perfil dos participantes da pesquisa, tem-se: maioria do gênero feminino com Ensino Superior completo, residente no Rio Grande do Sul, que viajou duas vezes ou mais por ano e geralmente com acompanhante. Houve um equilíbrio entre as faixas etárias e a renda mensal. A maior parte dos respondentes ou é casado ou é solteiro, viajou por prazer, vivenciou uma experiência turística memorável em um país da América do Sul, se hospedou em hotéis até quatro estrelas e investiu valores que variaram de $R \$ 1.000,00$ a $R \$ 7.000,00$ na viagem memorável.

A relação entre experiência turística memorável e práticas sustentáveis foi analisada por meio do coeficiente de correlação de Pearson, que identificou correlação significativa entre quase todos os construtos (práticas sustentáveis, experiência turística memorável, hedonismo, novidade, cultura local, conhecimento, renovação, significância, envolvimento). Apenas não houve correlação significativa entre os construtos práticas sustentáveis e o construto renovação. Das dimensões da experiência turística memorável, o conhecimento foi o que apresentou maior associação com as práticas sustentáveis.

Mesmo que a associação tenha sido considerada baixa, ainda assim houve significância positiva entre práticas sustentáveis e experiência turística memorável. Isso quer dizer que a tendência é que quanto maior for a experiência turística memorável, mais tende a ocorrer práticas sustentáveis e vice-versa.

Alguns pontos importantes em relação ao perfil dos respondentes podem ser citados: a maioria viaja com outras pessoas (família, cônjuge, namorado(a), amigos), ou seja, a experiência turística memorável pode estar relacionada, em grande parte, com questões de interação com pessoas a que se tem afeto, promovendo laços e redes de amizade e amor, o que está ligado também com a sustentabilidade.

Sobre o grau de escolaridade, ao que parece, o alto grau de estudo também implica uma busca por viagens turísticas. Se pudermos considerar que o estudo, muitas vezes, não nos traz apenas respostas, mas também dúvidas e lacunas a serem preenchidas na vida humana, o turismo pode ser uma forma de, por meio do conhecimento de novos lugares, povos e culturas, identificar-se e reconhecer-se a si mesmo, como citam Panosso Netto e Gaeta (2010, p. 23): “a viagem não é apenas um deslocamento geográfico, cultural ou social, mas uma jornada interior, o que justifica ser uma experiência fundamental na vida das pessoas". 
Quanto à renda mensal, o que se percebeu é que se torna possível vivenciar experiências turísticas memoráveis com qualquer faixa de renda, uma vez que não é fundamental viajar para muito longe a fim de obter essas experiências: uma viagem a uma cidade vizinha (e se considerarmos barata) também é capaz de proporcionar uma experiência turística memorável. Isso implica diretamente na sustentabilidade, posto que se percebe a possibilidade de se vivenciar experiências positivas por todas as classes sociais, ou seja, a oportunidade de proporcionar o lazer, a cultura, o conhecimento, a aprendizagem, o divertimento - principalmente se levarmos em conta que estamos unindo a diversão com a educação - se mostra acessível a uma significativa parcela da sociedade.

Quando se fala de turismo, logo se associa com diversão, lazer, descanso, que são necessários a todos os seres humanos. Ao considerar a importância de atividades relacionadas à diversão para o ser humano, tem-se, mais profundamente, a promoção da felicidade e a satisfação com a vida. É preciso ser feliz, e o turismo contribui muito com isso.

Esta pesquisa também contribui com a ideia de que é possível que a atividade turística promova aprendizado, e esse aprendizado deve ser repassado, transmitido, utilizado no dia a dia. As práticas sustentáveis devem ser incorporadas não somente à rotina diária das pessoas, em suas casas ou no seu trabalho, mas também devem se tornar parte de uma cultura que preza pela competência sustentável, e isto pode ser alcançado principalmente por meio da aprendizagem, do conhecimento e da ampliação do escopo de atuação, ou seja, a família, a casa, o trabalho, os amigos, a rua em que se anda, o mercado que se frequenta, a cidade em que se vive, a cidade para a qual se viaja.

No âmbito econômico, este trabalho contribuiu para a identificação dos aspectos que tornam uma viagem mais memorável. Diante disso, empresas turísticas podem desenvolver estratégias para captar e manter clientes. De tal modo, geram renda não somente para si, mas também para todas as organizações que o turismo contempla de maneira direta ou indireta.

Nos âmbitos ambiental e social, a constatação das práticas sustentáveis, realizadas pelos turistas, possibilita que organizações públicas e privadas reflitam sobre como incentivar a preservação da natureza, a educação, a atenção à comunidade local e a valorização histórico-cultural. Por fim, estudos como este também beneficiam o turista e a própria destinação, considerando que as experiências poderão ser facilitadas a fim de se tornarem memoráveis e o destino mais sustentável para que a atividade turística possa continuar acontecendo.

\section{REFERÊNCIAS}

AROEIRA, T.; DANTAS, A. C.; GOSLING, M. de S. Experiência turística memorável, percepção cognitiva, reputação e lealdade ao destino: um modelo empírico. Revista Turismo - Visão e Ação, Balneário Camboriú, v. 18, n. 3, p. 584-610, set./dez. 2016. Disponível em: http://siaiap32.univali.br/seer/index.php/rtva/ article/viewFile/ 9194/5106. Acesso em: 19 mar. 2017.

BRASIL. Casa Civil. Lei no 8.069, de 13 de julho de 1990. Dispõe sobre o Estatuto da Criança e do Adolescente e dá outras providências. Diário Oficial da República Federativa do Brasil, Brasília, DF, 13 jul. 1990. Disponível em: http://www.planalto.gov.br/ccivil_03/leis//8069.htm. Acesso em: 25 mar. 2018.

BRASIL. Casa Civil. Lei no 10.741, de 10 de outubro de 2003. Dispõe sobre o Estatuto do Idoso e dá outras providências. Disponível em: http://www.planalto.gov.br/ccivil_03/leis/2003/I10.741.htm. 
BRASIL. Ministério do Turismo. MTur apresenta mapa da sustentabilidade. 2016a. Disponível em: http:// www.turismo.gov.br/\%C3\%BAltimas-not\%C3\%ADcias/7010-minist\%C3\%A9rio-do-turismo-apresenta-mapa-da-sustentabilidade.html. Acesso em: 21 jan. 2017.

BRASIL. Pesquisa de hábitos de consumo do turismo brasileiro. 2009. Disponível em: http://www.turismo.gov.br/sites/default/turismo/noticias/todas_noticias/Noticias_download/13.11.09_Pesquisa_Hxbitos_2009.pdf. Acesso em: 13 fev. 2018.

BRASIL. Turismo e sustentabilidade: orientações para prestadores de serviços turísticos. Brasília, DF, 2016b. Disponível em: http://www.turismo.gov.br/images/ pdf/06_06_2016_mtur_guia_turismo_sustentabilidade.pdf. Acesso em: 17 mar. 2017.

CARVALHO, C. L. Breves histórias do turismo brasileiro. In: TRIGO, L. G. G. et al. Análises regionais e globais do turismo brasileiro. São Paulo: Roca, 2005.

CNC. Confederação Nacional do Comércio de Bens, Serviços e Turismo. Estudos em turismo: turismo e sustentabilidade. Rio de Janeiro: Confederação Nacional do Comércio de Bens, Serviços e Turismo, 2014. Disponível em: http://www.cnc.org.br/sites /default/files/arquivos/estudos_em_turismo_turismo _e_ sustentabilidade.pdf. Acesso em: 8 out. 2015.

CUNHA, F. M. Para além da participação: aprendizagem social na gestão de recursos hídricos. 2009. 194f. Tese (Doutorado Ciência Ambiental) - Universidade de São Paulo, São Paulo, SP, 2009. Disponível em: http://www.teses.usp.br/teses/disponiveis/ 90/90131/tde-17062011-172722/pt-br.php. Acesso em: 13 set. 2015

ELKINGTON, J. Canibais de garfo e faca. São Paulo: Makron Books, 2001.

GIL, A. C. Métodos e técnicas de pesquisa social. São Paulo: Atlas, 2008.

HAIR JR., J. F.; BLACK, W. C.; BABIN, B. J.; ANDERSON, R. E.; TATHAM, R. L. Análise multivariada de dados. 6. ed. Porto Alegre: Bookman, 2009.

JACKSON, T. Live Better by Consuming Less? Is There a "Double Dividend" in Sustainable Consumption? Journal of Industrial Ecology, v. 9, n. 1-2, p. 19-36, 2005. Disponível em: http://onlinelibrary.wiley.com/ doi/10.1162/1088198054084734/epdf. Acesso em: 15 mar. 2017.

KIM, J. H. Development of a scale to measure memorable tourism experiences. 2009. 141f. Tese (Doutorado de Filosofia em Comportamento de Lazer) - Indiana University. School of Health, Physical Education, and Recreation, Indiana, 2009. Disponível em: https://scholarworks.iu.edu/dspace/bitstream/handle/2022/8786/Kim_indiana_0093A_10479.pdf?sequ. Acesso em: 17 mar. 2017.

LOPES, L. F. D. Métodos quantitativos. 1. ed. Santa Maria: UFSM, 2016.

OMT. Organização Mundial do Turismo. Guia de desenvolvimento do turismo sustentável. Trad. Sandra Nertz. Porto Alegre: Bookman, 2003.

PANOSSO NETTO, A.; GAETA, C. Turismo de experiência. São Paulo: Senac, 2010.

PESTANA, M. H.; GAGEIRO, J. N. Análise de dados para ciências sociais: a complementariedade do SPSS. Lisboa: Silabo, 2003.

RIBEIRO, J. A.; VEIGA, R. T. Proposição de uma escala de consumo sustentável. Revista de Administração da Universidade de São Paulo, v. 46, n. 1, p. 45-60, jan./fev./mar. 2011. Disponível em: http://200.232.30.99/ download.asp?file=pg_45-60.pdf. Acesso em: 15 mar. 2017.

SILVA, N. G.; MONTICELLI, J. M. O turismo sustentável na percepção do viajante Gaúcho. Revista de Turismo Contemporâneo, Natal, v. 4, n. 2, p. 262-285, jul./dez. 2016.

SWARBROOKE, J. Turismo sustentável: conceitos e impacto ambiental. São Paulo: Aleph, 2000. Vol. 1. SWARBROOKE, J.; HORNER, S. O comportamento do consumidor no turismo. São Paulo: Aleph, 2002. URRY, J. O olhar do turista: lazer e viagens nas sociedades contemporâneas. Trad. Carlos Eugênio Marcondes de Moura. São Paulo: Studio Nobel; Sesc, 2001.

VIANNA, S. L. G. A competitividade e a qualidade de vida na destinação turística: análise quanto à sua correspondência. 2011. 336f. Tese (Doutorado em Administração e Turismo) - Universidade do Vale do Itajaí, Biguaçu, 2011. Disponível em: https://siaiap39.univali.br/repositorio/bitstream/repositorio/2194/1/ Silvio\%20Luiz\%20Goncalves\%20Vianna.pdf. Acesso em: 23 jan. 2018. 